\title{
Breast Cancer: Risk Factors, Diagnosis and Management
}

Behrouz Farhadihosseinabadi (PhD) Department of Pharmacology, School of Medicine, Shahid Beheshti University of Medical Sciences, Tehran, Iran

Fahimeh Hosseini (BSc)

Gonabad University of Medical Sciences, Gonabad, Iran

Pegah Larki (PhD)

Basic and Molecular Epidemiology of Gastrointestinal Disorders Research Center, Research Institute for Gastroenterology and Liver Diseases, Shahid Beheshti University of Medical Sciences, Tehran, Iran

Nader Bagheri (PhD)

Cellular and Molecular Research

Center, Basic Health Sciences Institute, Shahrekord University of Medical

Sciences, Shahrekord, Iran

Kazem Abbaszadeh-Goudarzi (PhD)

Cellular and Molecular Research

Center, Sabzevar University of

Medical Sciences, Sabzevar, Iran

Koushan Sinehsepehr (PhD)

Laboratory Sciences Research Center,

Golestan University of Medical

Sciences, Gorgan, Iran

Behrooz Johari (PhD)

Department of Medical Biotechnology

and Nanotechnology, School of

Medicine, Zanjan University of

Medical Science, Zanjan, Iran

Meghdad Abdollahpour-Alitappeh

(PhD)

Department of Nursing, School of

Nursing, Larestan University of

Medical Sciences, Larestan, Iran

Corresponding author: Meghdad

Abdollahpour-Alitappeh,

Tel: +9871-52342877

Email:Abdollahpour1983@yahoo.com

Address: Larestan University of

Medical sciences, Larestan, Iran. P.O.

Received : 23 Apr 2018

Revised: 01 Jun 2018

Accepted: 30 Jun 2018

\section{ABSTRACT}

Breast cancer remains the most common cancer of women and one of the most common causes of cancer-related deaths worldwide. In spite of major advances in breast cancer diagnosis and treatment, the incidence of breast cancer remains high and the treatment of metastatic breast cancer remains challenging. This review presents an overview of breast cancer with a particular focus on its clinical aspects and therapies.

Keywords: Breast Cancer, Risk Factors, Diagnosis, Treatment.

This paper should be cited as: Farhadihosseinabadi B, Hosseini F, Larki P, Bagheri N, Abbaszadeh-Goudarzi K, Sinehsepehr K, Johari B, Abdollahpour-Alitappeh M [Breast Cancer: Risk Factors, Diagnosis and Management]. mljgoums. 2018; 12(5):1-9 


\section{INTRODUCTION}

Cancer is a group of more than 100 diseases characterized by uncontrolled growth and spread of abnormal immortal cells (1). Earliest reports of cancer are believed to go back to $1600 \mathrm{BC}$ in the Edwin Smith papyrus. Nevertheless, the origin of the word "cancer" is credited to the Hippocratic physicians, who used the terms karkinos (nonhealing swelling or ulcerous formation) and karkinoma (nonhealing cancer) to define tumors (2). Galen, a Greek physician, surgeon and philosopher in the Roman Empire, believed that cancer may occur in any part of the body, but it frequently occurs in the breasts of women whose menstruation was abnormal or inexistent (2).

Cancer is currently considered as a major public health problem worldwide. It is the second leading cause of death in the United States (3) and its prevalence is increasing without a satisfactory treatment (1). At present, there are more than 100 cancer types, including breast cancer, skin cancer, lung cancer, colon cancer, prostate cancer and lymphoma. Most types of cancer cells form a lump or mass called a tumor, and are named after the part of the body where the tumor originates (4). In general, all tumor cells show the six hallmarks of cancer including cell growth and division in the absence of proper signals, continuous growth and division even in the presence of contrary signals, the absence of programmed cell death, unlimited cell divisions, the sprouting of new blood vessels, and invasion of normal tissues as well as establishment of metastasis (5).

Breast cancer is a heterogeneous disease, which has been first described by the ancient Egyptians more than 3,500 years ago. The earliest record of breast cancer stems from the Edwin Smith surgical papyrus (Egyptian time 2500-3000 BC) (6). The present review provides an overview of breast cancer with a particular focus on its clinical and diagnostic features, risk factors and therapies.

\section{Breast Cancer Statistics}

Breast cancer is the most common cancer among women with approximately 1.7 million new cases diagnosed in 2012, accounting for $23 \%$ of all cancer cases. The mortality rates of breast cancer have increased by $14 \%$ and it is currently ranked as the fifth cause of cancerrelated deaths (7). The overall risk of breast cancer doubles each decade until the menopause, after which the increase slows down or remains stable. Nevertheless, breast cancer is more common in postmenopausal women. Studies of women who migrated from low-risk to high-risk areas demonstrated that breast cancer incidence adjusts to the incidence rate in the host country within one or two generations, indicating the importance of lifestyle and environmental factors in the progression of the disease $(8,9)$. According to Globocan, 70,218 deaths in India were due to breast cancer in 2012, exceeding statistics in China (47,984 deaths) and the United States (43,909 deaths) (10). In 2016, an estimated $1,685,210$ new cases was expected to be diagnosed, because of which 595,690 people would die in the United States (11). In Iran, breast cancer mortality rates increased from 1.97 per 100,000 in 2006 to 2.45 per 100,000 in 2010 (12). Figure 1 presents total cancer registries in Iran according to the International Agency for Research on Cancer statistics in 2012 (13).

\section{Breast Cancer Classification}

Breast cancer is classified into categories according to different schemes, each based on different criteria with various purposes. The most important categories are the histopathological type, the tumor grade, the tumor stage and the expression of certain proteins and genes. As knowledge of cancer cell biology develops, these classifications are updated $(14,15)$. However, breast cancer can be broadly categorized into in situ (noninvasive) carcinoma and invasive (infiltrating) carcinoma.

\section{In situ carcinoma}

Non-invasive cancers stay within the milk ducts or lobules of the breast, and do not invade normal tissues within or beyond the breast. Breast carcinoma in situ is further subclassified into either ductal carcinoma in situ or lobular carcinoma in situ (15).

\section{Invasive carcinoma}

Most breast cancers are invasive, in which cancer cells break through the walls of the glands or ducts where they originated, and grow into the surrounding breast tissue. The most common invasive breast cancers include invasive ductal carcinoma and invasive lobular carcinoma (16-18).

Signs and Symptoms of Breast Cancer Breast cancer generally show no symptoms when the tumor is small. Once the tumor 
grows to a size that can be felt, a painless lump is the most common physical sign. Nevertheless, breast cancer symptoms vary from person to person. Common signs and symptoms include skin changes (such as swelling, redness or other visible differences in one or both breasts), enlargement or change in shape of the breast, skin irritation or dimpling, change in the appearance of one or both nipples, general pain in/on any part of the breast, breast or nipple pain, nipple retraction (turning inward), redness, scaliness or thickening of the nipple or breast skin, nipple discharge (other than breast milk) and lumps or nodes felt on or inside of the breast. In addition, symptoms more specific to invasive breast cancer include irritated or itchy breasts, change in breast color, enlargement or change in shape of the breast, changes in touch (hard, tender or warm), peeling or flaking of the nipple skin, a breast lump or thickening and redness or pitting of the breast skin $(19,20)$.

\section{Breast Cancer Risk Factors}

A great number of factors are known to increase the risk of breast cancer. Factors associated with an increased or decreased risk of breast cancer include personal and family history (genetic predisposition, personal history of breast cancer, ductal or lobular carcinoma in situ, benign breast disease, endogenous hormone levels, menstrual cycles and bone mineral density), reproductive factors (pregnancy, fertility drugs, breastfeeding, hormonal birth control and postmenopausal hormones), environmental factors (radiation, diethylstilbestrol exposure, environmental pollutants and occupational exposures) and other risk factors (tobacco use, obesity, physical activity, diet and alcohol consumption).

\section{Breast Cancer Diagnosis}

Breast cancer is typically diagnosed either before symptoms start to appear (during screening examinations) or after women notice a lump. Most masses are found on mammogram, and most breast lumps turn out to be benign. In general, when cancer is suspected, microscopic analysis of breast tissue is required to establish a definitive diagnosis, to determine the extent of spread (in situ or invasive) and to characterize the type of the disease (21).

\section{Mammography}

Most breast cancers are diagnosed after suspicious findings from a screening mammography. Women exhibiting abnormal screening mammograms should regularly undergo further evaluation (22).

Medical History and Physical Examination

Evaluation of a patient with suspected breast cancer begins with a complete medical history taking. A visual and manual inspection of the breasts should be conducted for the possible presence of lumps or masses, asymmetry, changes to the skin or nipples and tenderness (23).

\section{Imaging Tests}

Diagnostic mammogram and breast ultrasound are generally used to assess an abnormal breast. Other imaging devices such as magnetic resonance imaging, ductogram, scintimammography and molecular breast imaging may be applied along with the above tests to improve diagnostic accuracy (24).

\section{Breast Biopsy}

In some cases, breast imaging can determine that an abnormality is not cancer. Nonetheless, imaging tests alone cannot prove that a lesion is malignant. Breast biopsy is the only definitive method of diagnosing breast cancer, which removes tissue or cells for microscopic examination. There are several different types of breast biopsies, including needle biopsy (fine needle aspiration biopsy and core needle biopsy), image-guided biopsy and surgical biopsy (25).

Tissue Markers

In 2007, the American Society of Clinical Oncology updated the recommendations for the use of tumor markers as prognostic factors. Markers of clinical utility include CA 15-3, CA 27.29, carcinoembryonic antigen, estrogen receptor (ER), progesterone receptor (PR), human epidermal growth factor receptor-2 (HER2), urokinase plasminogen activator, plasminogen activator inhibitor and certain multiparameter gene expression assays. Hormone receptor status and HER2 are the major tissue markers used for breast cancer diagnosis (26).

\section{Genomic Profiles}

Molecular subtypes of breast cancer are based on molecular features but not the tumor's microscopic appearance. Four molecular subtypes have been identified including luminal A, luminal B, HER2-enriched and basal-like breast cancer (27).

Gene Expression Profiles

Gene expression tests are applied to predict the possible recurrence of early-stage breast 
cancer after initial treatment. The three most commonly tests used for this purpose include the Oncotype Dx, MammaPrint and PAM50 (28).

\section{Staging of Breast Cancer}

Staging is the process of determining the growth, extent and location of cancer in the body. The stage of cancer is one of the most important factors for planning effective treatment. TNM is the most widely used system for breast cancer staging. It stands for tumor (T), lymph nodes $(\mathrm{N})$ and metastasis (M), each of which is followed by a number and sometimes additional letters. By definition, $\mathrm{T}, \mathrm{N}$ and $\mathrm{M}$ components designate the size and invasiveness of the primary tumor, the presence or absence of regional node involvement and the presence or absence of distant metastasis, respectively. When the values for $\mathrm{T}, \mathrm{N}$ and $\mathrm{M}$ are established, the information is grouped and stated as one of five possible stages represented by Roman numerals from Stage 0 to Stage IV (29). In addition, five-year survival rates refer to the percentage of patients who lives for at least 5 years from diagnosis. An approximate 5-year relative survival rate for various stages of breast cancer includes 100\%, 100\%, 93\%, $72 \%$ and $22 \%$ for stages 0 , I, II, III, and IV, respectively (30).

\section{Breast Cancer Treatment}

Treatment decisions are made based on the stage and biological characteristics of cancer, patient's age, and the risks and benefits. Most women with early stage breast cancer will undergo some type of surgery, which is often combined with other treatments such as radiation therapy, chemotherapy, hormonal (endocrine) therapy and/or targeted therapy. Patients with metastatic cancer are primarily treated with systemic therapies including chemotherapy, targeted therapy or hormonal therapy.

Surgery

Breast cancer surgery is carried out to remove the cancer from the breast and to determine the stage of disease. Surgical treatment for breast cancer involves mastectomy or breastconserving surgery (BCS). Only cancerous tissues plus a rim of normal tissue are removed in BCS, while the entire breast is removed in mastectomy. However, there is a higher risk of local recurrence (cancer returning to the breast) with BCS compared with mastectomy. Younger women (under 40 years of age) and patients with larger and/or more aggressive tumors are more likely to undergo mastectomy. Both BCS and mastectomy are usually accompanied with removal of one or more regional lymph nodes from the armpit (or axilla) to determine if the disease has spread beyond the breast. The presence of any cancer cells in the lymph nodes will help determine the need for subsequent surgery, radiation and medical treatments (31).

\section{Radiation therapy}

Radiation therapy exerts high-energy beams or particles to kill cancer cells. Such therapy is often performed following surgery to destroy remaining cancer cells in the breast, chest wall or underarm area. BCS is usually followed by radiation therapy because it reduces the risk of recurrence and death by about $50 \%$ and $20 \%$, respectively. Some mastectomy-treated patients also benefit from radiation if their tumor is larger than $5 \mathrm{~cm}$ or if cancer is found in the lymph nodes. In addition, radiation can be used to treat the symptoms of advanced breast cancer, especially when it has spread to the central nervous system or bones (32).

\section{Systemic therapy}

In systemic therapy, a drug can reach and affect cells in all parts of the body through the bloodstream. The drugs are injected into a vein or given orally. If given to patients before surgery, systemic treatment is regarded as neoadjuvant or preoperative therapy. Neoadjuvant systemic therapy was found to be as effective as the therapy given after surgery (adjuvant therapy) in terms of survival, disease progression and distant recurrence. Systemic therapy includes chemotherapy, hormonal therapy and targeted therapy, all of which work through different mechanisms (33).

\section{Chemotherapy}

Chemotherapeutic drugs generally act by attacking cells that grow quickly, such as cancer cells. The benefit of chemotherapy depends on multiple factors, including the tumor size, the number of lymph nodes involved, the presence of estrogen or progesterone receptors and the amount of HER2 protein produced by the cancer cells. Triple negative (ER-, PR- and HER2-negative) and HER2-positive breast cancers tend to be more sensitive to chemotherapy, while ER+ and PR+ tumors are generally less responsive. There is evidence suggesting that combination of drugs can be more effective than singledrug therapies for the treatment of early-stage 
breast cancer. Based on the combination of drugs used, adjuvant and neoadjuvant chemotherapy is usually given for 3-6 months (34).

\section{Hormonal therapy}

Hormonal therapy works by either blocking the body's natural hormones or lowering their levels. Estrogen leads to the increased growth of ER+/PR+ breast cancers. Hormonal therapy is given to patients with $\mathrm{ER}+\mathrm{PR}+$ breast cancer to decrease estrogen levels or block the effect of estrogen on the growth of breast cancer cells. Tamoxifen is capable of blocking the effects of estrogen, and is routinely used for the treatment of premenopausal and postmenopausal cancers. Aromatase inhibitors including letrozole, anastrozole and exemestane are another class of drugs used for the treatment of both early and advanced hormone receptor-positive breast cancer (35).

Targeted therapy

Since cancer is often presented as a disseminated disease, it is crucial to target both the primary tumor cells and the distant metastases, while sparing non-tumor cells. Everolimus (Afinitor) can help stop angiogenesis and cancer cell growth by blocking mTOR, a protein that promotes cell growth and division. It is currently suggested for women whose cancers have grown while being treated with letrozole or anastrozole (38, 39).

Targeted therapy for HER2-positive breast cancer

HER2 is a tyrosine kinase receptor and a member of the HER (or ErbB) family of growth factor receptors. This $185 \mathrm{kDa}$ transmembrane oncoprotein is encoded by the HER 2/neu gene. This family of receptors consists of four distinct receptors: the epidermal growth factor receptor 1 (EGFR 1) or ErbB1, HER2 (or ErbB2), HER3 (or ErbB3) and HER4 (or ErbB4). Homo- or hetero-dimerization of these receptors results in phosphorylation of residues from the intracellular domain of the receptor, leading to recruitment of signaling molecules from the cytoplasm and initiation of several signaling pathways. HER2 dimerization triggers a number of processes in the cell, culminating in increased cell motility, survival and proliferation, as well as resistance to apoptosis. HER2 is overexpressed in approximately 20$25 \%$ of invasive breast cancers (40-42). Such tumors are aggressive with rapid growth and early metastasis with frequent spread to the central nervous system.

HER2-positive tumors are typically treated with therapies that inhibit HER2 signaling along with chemotherapy (43). Inhibition of the HER2 antiapoptosis activity by targeted therapy provides additive or synergistic effects when combined with certain chemotherapeutic drugs $(44,45)$. A number of drugs have been developed to target this protein, which are described below.

Lapatinib (Tykerb) is a small molecule and a member of the 4-anilinoquinazoline class of kinase inhibitors. As a dual tyrosine kinase inhibitor, lapatinib interrupts the HER2/neu and EGFR pathways (46). One of the most successful strategies in the development of targeted therapies has been the production of $\mathrm{mAbs}$ directed against epitopes present on tumor cells. Antibody-based therapies targeting HER2 rely on the development of mAbs against epitopes present in the HER2 extracellular domain. After binding to their cognate epitopes, such antibodies exert their antitumor effects via a variety of mechanisms. Trastuzumab (Herceptin) is a humanized IgG1 kappa light chain $\mathrm{mAb}$ in which the complementary-determining regions of a HER2-specific mouse mAb were joined to human antibody framework regions through genetic engineering (47).

Figure 1- Distribution of the most frequent cancers in the Iranian population

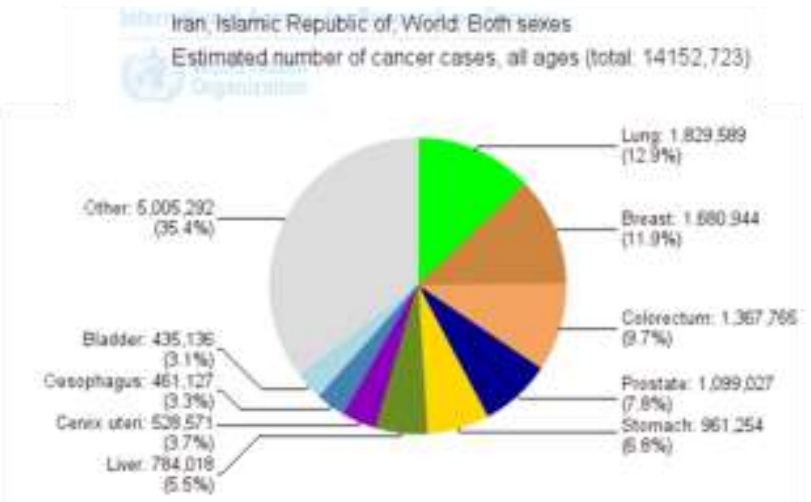


The humanized mAb trastuzumab was the first FDA-approved targeted therapy for the treatment of HER2-overexpressing breast cancer in adjuvant and metastatic settings (48, 49). Trastuzumab binds to the extracellular domain of HER2 and inhibits proliferation of cultured HER2-positive breast cancer cells (50). The molecular mechanism through which trastuzumab inhibits cell signaling is not fully understood $(51,52)$. The combined results of two large trials indicated that trastuzumab along with standard chemotherapy are able to reduce the risk of recurrence and death by $52 \%$ and $33 \%$ for early stage HER2-positive breast cancer, respectively, when compared with chemotherapy alone. However, although trastuzumab is effective in HER2-positive breast cancer, $70 \%$ of patients with HER2positive breast cancers stop responding or lose clinical benefits because of primary (denovo) or secondary (acquired) resistance. Mechanisms for resistance are grouped into four main categories: (1) obstacles preventing trastuzumab-binding to HER2, (2) alternative signaling pathways, (3) upregulation of HER2 downstream signaling pathways and (4) failure to trigger an immune-mediated mechanism to destroy tumor cells (53). The type of resistance varies depending on the type of tumor antigen and pathway, which can be either genetic (i.e. mutations in target antigen/downstream proteins) (54) or non-genetic (i.e. activation of compensatory signaling) $(55,56)$.

Pertuzumab (Perjeta) is a more recently approved $\mathrm{mAb}$ that seems to attach to a different location on the HER2 protein. Pertuzumab can be given either before surgery to treat early-stage breast cancer, or to treat advanced breast cancer. The mAb pertuzumab binds to the HER2 heterodimer and prevents dimerization with EGFR. HER2-HER3 dimer is potent activator of the PI3K pathway. Although pertuzumab has single-agent activity, most clinical trials have focused on it combination with trastuzumab to obtain a more complete blockade of HER receptor signaling (57).
Trastuzumab emtansine (ado-trastuzumab emtansine or Kadcyla ${ }^{\mathrm{TM}}$ ) is an antibody-drug conjugate (ADC) consisting of trastuzumab conjugated to the cytotoxic agent emtansine. It is proposed that a HER2 antibody-cytotoxic drug conjugate would deliver the cytotoxic agent directly to tumor cells to circumvent resistance to $\mathrm{mAbs}$ because most $\mathrm{mAbs}$ have little antitumor activity on their own, even after binding to the target antigen.

ADCs are complex molecules composed of an antibody conjugated to a biologically active cytotoxic payload or drug. Typically, the cytotoxins used in ADCs are 100-1000 times more potent than regular chemotherapeutics, and preferably have sub-nanomolar potency. Most classes of cytotoxins used in the ADC structure serve as microtubule inhibitors (such as auristatins and maytansinoids) or DNAdamaging agents (such as anthracyclines and calicheamicins) (58-61). Moreover, various other mAbs, ADCs and small molecules are now being studied in HER2-positive breast cancer (62).

\section{CONCLUSION}

Breast cancer is the most common type of cancer in women. Although it can also occur in men, it is far more common in women. A variety of treatment options is currently used for patients with breast cancer, but there is a need for development of tailored targeted therapies (such as ado-trastuzumab emtansine). Such treatments require an improved understanding of the target antigens present on the surface of tumor cells. It is of great value to generate specific small molecules and antibody-based therapies for treatment of patients with breast cancer.

\section{ACKNOWLEDGEMENTS}

We would like to thank Dr. Saeed Jahandideh for his helpful comments.

\section{CONFLICT OF INTEREST}

All authors declare that there is no conflict of interest. 


\section{References}

1. Ogur R. Studies with Myrtus communis L.: Anticancer properties. J Intercult Ethnopharmacol. 2014; 3(4): 1357. doi: $10.5455 /$ jice.20140803044831.

2. Papavramidou N, Papavramidis $\mathrm{T}$, Demetriou $\mathrm{T}$. Ancient Greek and Greco-Roman methods in modern surgical treatment of cancer. Ann Surg Oncol. 2010; 17(3): 665-7. https://doi.org/10.1245/s10434-009-08866.

3. Siegel RL, Miller KD, Jemal A. Cancer statistics, 2016. CA: a cancer journal for clinicians. 2016; 66(1): 7 30.https://doi.org/10.3322/caac.21332.

4. GM C. The Cell: A Molecular Approach. $2^{\text {nd }}$ ed. 2000. 5. Hanahan D, Weinberg RA. The hallmarks of cancer. Cell. 2000; 100(1): 57-70.

https://doi.org/10.1016/S0092-8674(00)81683-9

6. Akram M, Siddiqui SA. Breast cancer management: past, present and evolving. Indian journal of cancer. 2012; 49(3): 277-82.https://doi.org/10.4103/0019509X.104486.

7. Ferlay J, Soerjomataram I, Dikshit R, Eser S, Mathers $\mathrm{C}$, Rebelo $\mathrm{M}$, et al. Cancer incidence and mortality worldwide: sources, methods and major patterns in GLOBOCAN 2012. Int J Cancer. 2015; 136(5): E359-86. doi: 10.1002/ijc.29210.

8. McPherson K, Steel CM, Dixon JM. ABC of breast diseases. Breast cancer-epidemiology, risk factors, and genetics. Bmj. 2000; 321(7261): 6248.https://doi.org/10.1136/bmj.321.7261.624.

9. Visser O, van der Kooy K, van Peppen AM, Ory FG, van Leeuwen FE. Breast cancer risk among firstgeneration migrants in the Netherlands. British journal of cancer. 2004; 90(11): 2135-7.

https://doi.org/10.1038/sj.bjc.6601821.

10. Donepudi MS, Kondapalli K, Amos SJ, Venkanteshan P. Breast cancer statistics and markers. Journal of cancer research and therapeutics. 2014; 10(3): 506-11. doi: 10.4103/0973-1482.137927.

11. Torre LA, Bray F, Siegel RL, Ferlay J, LortetTieulent J, Jemal A. Global cancer statistics, 2012. CA: a cancer journal for clinicians. 2015; 65(2): 87108.https://doi.org/10.3322/caac.21262.

12. Enayatrad M, Amoori N, Salehiniya H. Epidemiology and trends in breast cancer mortality in iran. Iranian journal of public health. 2015; 44(3): 430-1.

13. WHO. Cancer IAfRo 2012. Available from: https://www.iarc.fr/.

14. Weigelt B, Horlings HM, Kreike B, Hayes MM, Hauptmann M, Wessels LF, et al. Refinement of breast cancer classification by molecular characterization of histological special types. The Journal of pathology. 2008; 216(2): 141-50.https://doi.org/10.1002/path.2407.

15. Malhotra GK, Zhao X, Band H, Band V. Histological, molecular and functional subtypes of breast cancers. Cancer biology \& therapy. 2010; 10(10): 95560.https://doi.org/10.4161/cbt.10.10.13879.

16. Sinn HP, Kreipe H. A Brief Overview of the WHO Classification of Breast Tumors. $4^{\text {th }}$ ed. Breast care. 2013; 8(2):149-54.https://doi.org/10.1159/000350774.

17. McCart Reed AE, Kutasovic JR, Lakhani SR, Simpson PT. Invasive lobular carcinoma of the breast: morphology, biomarkers and 'omics. Breast cancer research : BCR. 2015; 17(1):12. doi: 10.1186/s13058015-0519-x. https://doi.org/10.1186/s13058-015-0519-x.
18. Arpino G, Bardou VJ, Clark GM, Elledge RM. Infiltrating lobular carcinoma of the breast: tumor characteristics and clinical outcome. Breast cancer research : BCR. 2004; 6(3): R149-56.

https://doi.org/10.1186/bcr767.

19. Singh D, Malila N, Pokhrel A, Anttila A. Association of symptoms and breast cancer in population-based mammography screening in Finland. International journal of cancer. 2015; 136(6): E630-7. https://doi.org/10.1002/ijc.29170.

20. Sharma GN, Dave R, Sanadya J, Sharma P, Sharma KK. Various types and management of breast cancer: an overview. Journal of advanced pharmaceutical technology \& research. 2010; 1(2): 109-26.

21. Neal L, Tortorelli CL, Nassar A. Clinician's guide to imaging and pathologic findings in benign breast disease. Mayo Clinic proceedings. 2010; 85(3): 2749.https://doi.org/10.4065/mcp.2009.0656

22. Jorgensen KJ. Mammography screening. Benefits, harms, and informed choice. Danish medical journal. 2013; 60(4): B4614.

23. Rosenzweig MQ, Gardner D, Griffith B. The History and Physical in Cancer Care: A Primer for the Oncology Advanced Practitioner. J Adv Pract Oncol. 2014; 5(4): 262-8.

24. Salem DS, Kamal RM, Mansour SM, Salah LA, Wessam R. Breast imaging in the young: the role of magnetic resonance imaging in breast cancer screening, diagnosis and follow-up. J Thorac Dis. 2013; 5 Suppl 1: S9-S18.

25. Palmer ML, Tsangaris TN. Breast biopsy in women 30 years old or less. American journal of surgery. 1993; 165(6): $\quad$ 708-12.https://doi.org/10.1016/S00029610(05)80793-7.

26. Vaidyanathan K, Vasudevan DM. Organ Specific Tumor Markers: What's New? Indian journal of clinical biochemistry: IJCB. 2012; 27(2): 11020.https://doi.org/10.1007/s12291-011-0173-8.

27. Yersal O, Barutca S. Biological subtypes of breast cancer: Prognostic and therapeutic implications. World journal of clinical oncology. 2014; 5(3): 41224.https://doi.org/10.5306/wjco.v5.i3.412.

28. Kittaneh M, Montero AJ, Gluck S. Molecular profiling for breast cancer: a comprehensive review. Biomarkers in cancer. 2013; 5: 6170.https://doi.org/10.4137/BIC.S9455

29. Gajdos C, Tartter PI, Bleiweiss IJ, Bodian C, Brower ST. Stage 0 to stage III breast cancer in young women. Journal of the American College of Surgeons. 2000; 190(5): $\quad 523-9 . \quad$ https://doi.org/10.1016/S10727515(00)00257-X

30. Chen L, Linden HM, Anderson BO, Li CI. Trends in 5-year survival rates among breast cancer patients by hormone receptor status and stage. Breast Cancer Res Treat. 2014; 147(3): 609-16. https://doi.org/10.1007/s10549-014-3112-6.

31. McGuire KP, Santillan AA, Kaur P, Meade T, Parbhoo J, Mathias M, et al. Are mastectomies on the rise? A 13-year trend analysis of the selection of mastectomy versus breast conservation therapy in 5865 patients. Ann Surg Oncol. 2009; 16(10): 2682-90. https://doi.org/10.1245/s10434-009-0635-x. 
32. Early Breast Cancer Trialists' Collaborative G, Darby S, McGale P, Correa C, Taylor C, Arriagada R, et al. Effect of radiotherapy after breast-conserving surgery on 10-year recurrence and 15-year breast cancer death: meta-analysis of individual patient data for 10,801 women in 17 randomised trials. Lancet. 2011; 378(9804): $\quad$ 1707-16.https://doi.org/10.1016/S01406736(11)61629-2.

33. Mauri D, Pavlidis N, Ioannidis JP. Neoadjuvant versus adjuvant systemic treatment in breast cancer: a meta-analysis. J Natl Cancer Inst. 2005; 97(3): 188-94.

34. von Minckwitz G, Eidtmann H, Rezai M, Fasching $\mathrm{PA}$, Tesch H, Eggemann $\mathrm{H}$, et al. Neoadjuvant chemotherapy and bevacizumab for HER2-negative breast cancer. The New England journal of medicine. 2012; 366(4): 299309.https://doi.org/10.1056/NEJMoa1111065

35. Abdulkareem IH, Zurmi IB. Review of hormonal treatment of breast cancer. Niger J Clin Pract. 2012; 15(1): 9-14. https://doi.org/10.4103/1119-3077.94088.

36. Kim EG, Kim KM. Strategies and Advancement in Antibody-Drug Conjugate Optimization for Targeted Cancer Therapeutics. Biomolecules \& therapeutics. 2015; 23(6): 493-509.

https://doi.org/10.4062/biomolther.2015.116

37. Finn RS, Crown JP, Lang I, Boer K, Bondarenko IM, Kulyk SO, et al. The cyclin-dependent kinase 4/6 inhibitor palbociclib in combination with letrozole versus letrozole alone as first-line treatment of oestrogen receptor-positive, HER2-negative, advanced breast cancer (PALOMA-1/TRIO-18): a randomised phase 2 study. The Lancet Oncology. 2015; 16(1): 25-35. https://doi.org/10.1016/S1470-2045(14)71159-3.

38. Baselga J, Semiglazov V, van Dam P, Manikhas A, Bellet M, Mayordomo J, et al. Phase II randomized study of neoadjuvant everolimus plus letrozole compared with placebo plus letrozole in patients with estrogen receptorpositive breast cancer. J Clin Oncol. 2009; 27(16): 26307.

https://doi.org/10.1200/JCO.2008.18.8391.

39. Bachelot T, Bourgier C, Cropet C, Ray-Coquard I, Ferrero JM, Freyer G, et al. Randomized phase II trial of everolimus in combination with tamoxifen in patients with hormone receptor-positive, human epidermal growth factor receptor 2-negative metastatic breast cancer with prior exposure to aromatase inhibitors: a GINECO study. J Clin Oncol. 2012; 30(22): 2718-24. https://doi.org/10.1200/JCO.2011.39.0708.

40. Olayioye MA, Neve RM, Lane HA, Hynes NE. The ErbB signaling network: receptor heterodimerization in development and cancer. The EMBO journal. 2000; 19(13): 3159-67.

https://doi.org/10.1093/emboj/19.13.3159

41. Schechter AL, Stern DF, Vaidyanathan L, Decker SJ, Drebin JA, Greene MI, et al. The neu oncogene: an erb$B$-related gene encoding a 185,000-Mr tumour antigen. Nature. 1984; 312(5994): 513-6. https://doi.org/10.1038/312513a0

42. Moasser MM. The oncogene HER2: its signaling and transforming functions and its role in human cancer pathogenesis. Oncogene. 2007; 26(45): 646987.https://doi.org/10.1038/sj.onc.1210477.
43. Rimawi MF, Schiff R, Osborne CK. Targeting HER2 for the treatment of breast cancer. Annual review of medicine. 2015; 66:111-28. https://doi.org/10.1146/annurev-med-042513-015127.

44. Pietras RJ, Pegram MD, Finn RS, Maneval DA, Slamon DJ. Remission of human breast cancer xenografts on therapy with humanized monoclonal antibody to HER-2 receptor and DNA-reactive drugs. Oncogene. 1998; 17(17): 223549.https://doi.org/10.1038/sj.onc.1202132.

45. Pegram M, Hsu S, Lewis G, Pietras R, Beryt M, Sliwkowski M, et al. Inhibitory effects of combinations of HER-2/neu antibody and chemotherapeutic agents used for treatment of human breast cancers. Oncogene. 1999; 18(13): 2241-51.https://doi.org/10.1038/sj.onc.1202526.

46. Burstein HJ, Storniolo AM, Franco S, Forster J, Stein $\mathrm{S}$, Rubin $\mathrm{S}$, et al. A phase II study of lapatinib monotherapy in chemotherapy-refractory HER2-positive and HER2-negative advanced or metastatic breast cancer. Ann Oncol. 2008; 19(6): 1068-74. https://doi.org/10.1093/annonc/mdm601.

47. Carter P, Presta L, Gorman CM, Ridgway JB, Henner $\mathrm{D}$, Wong WL, et al. Humanization of an anti-p185HER2 antibody for human cancer therapy. Proceedings of the National Academy of Sciences of the United States of America. $\quad 1992 ; \quad 89(10)$ : $4285-9$. https://doi.org/10.1073/pnas.89.10.4285.

48. Cobleigh MA, Vogel CL, Tripathy D, Robert NJ, Scholl S, Fehrenbacher L, et al. Multinational study of the efficacy and safety of humanized anti-HER2 monoclonal antibody in women who have HER2overexpressing metastatic breast cancer that has

progressed after chemotherapy for metastatic disease. $\mathrm{J}$ Clin Oncol. 1999; 17(9): 263948.https://doi.org/10.1200/JCO.1999.17.9.2639.

49. Fendly BM, Winget M, Hudziak RM, Lipari MT, Napier MA, Ullrich A. Characterization of murine monoclonal antibodies reactive to either the human epidermal growth factor receptor or HER2/neu gene product. Cancer research. 1990; 50(5): 1550-8.

50. Harari D, Yarden Y. Molecular mechanisms underlying ErbB2/HER2 action in breast cancer. Oncogene. 2000; 19(53): 610214.https://doi.org/10.1038/sj.onc.1203973.

51. Ghosh R, Narasanna A, Wang SE, Liu S, Chakrabarty A, Balko JM, et al. Trastuzumab has preferential activity against breast cancers driven by HER2 homodimers. Cancer research. 2011; 71(5): 187182. https://doi.org/10.1158/0008-5472.CAN-10-1872.

52. Bates M, Sperinde J, Kostler WJ, Ali SM, Leitzel K, Fuchs EM, et al. Identification of a subpopulation of metastatic breast cancer patients with very high HER2 expression levels and possible resistance to trastuzumab. Ann Oncol. 2011; 22(9): 2014-20. https://doi.org/10.1093/annonc/mdq706.

53. Pohlmann PR, Mayer IA, Mernaugh R. Resistance to Trastuzumab in Breast Cancer. Clin Cancer Res. 2009; 15(24): 7479-91. https://doi.org/10.1158/10780432.CCR-09-0636.

54. Reslan L, Dalle S, Dumontet C. Understanding and circumventing resistance to anticancer monoclonal antibodies. MAbs. 2009; 1(3): 2229.https://doi.org/10.4161/mabs.1.3.8292. 
55. Logue JS, Morrison DK. Complexity in the signaling network: insights from the use of targeted inhibitors in cancer therapy. Genes \& development. 2012; 26(7): 64150.

https://doi.org/10.1101/gad.186965.112

56. Gebleux R, Casi G. Antibody-drug conjugates: Current status and future perspectives. Pharmacology \& therapeutics. $\quad 2016$; 207 167 59.https://doi.org/10.1016/j.pharmthera.2016.07.012.

57. Cortes J, Fumoleau P, Bianchi GV, Petrella TM, Gelmon K, Pivot X, et al. Pertuzumab monotherapy after trastuzumab-based treatment and subsequent reintroduction of trastuzumab: activity and tolerability in patients with advanced human epidermal growth factor receptor 2-positive breast cancer. Journal of clinical $\begin{array}{llll}\text { oncology. } & 2012 ; & 30(14): & 1594-\end{array}$ 600.https://doi.org/10.1200/JCO.2011.37.4207.

58. Abdollahpour-Alitappeh M, Lotfinia M, RazaviVakhshourpour S, Jahandideh S, Najminejad H, Sineh Sepehr K, et al. Evaluation of Factors Influencing Antibody Reduction for Development of Antibody Drug Conjugates. Iranian biomedical journal. 2017; 21(4):
270-4. https://doi.org/10.18869/acadpub.ibj.21.4.270.

59. Abdollahpour-Alitappeh M H-AM, Balalaie S, Golmohammadi F, Lotfinia M, Abolhassani M. A new and simple non-chromatographic method for isolation of drug/linker constructs: vc-MMAE evaluation. J Herbmed Pharmacol. 2017; 6(4): 153-9.

60. Abdollahpour-Alitappeh M, Amanzadeh A, Heidarnejad F, Habibi-Anbouhi M, Lotfinia M, Razavivakhshourpour S, et al. Monomethyl Auristatin E, a Potent Cytotoxic Payload for Development of AntibodyDrug Conjugates against Breast Cancer. Novel Biomed. 2017; 5(3): 98-103.

61. Abdollahpour-Alitappeh M, Hashemi Karouei SM, Lotfinia M, Amanzadeh A, Habibi-Anbouhi M. A developed antibody-drug conjugate rituximab-vcMMAE shows a potent cytotoxic activity against CD20-positive cell line. Artif Cells Nanomed Biotechnol. 2018; 9: 1-8. https://doi.org/10.1080/21691401.2018.1449119

62. Zhang X, Munster PN. New protein kinase inhibitors in breast cancer: afatinib and neratinib. Expert opinion on pharmacotherapy. 2014; 15(9): 1277-88. https://doi.org/10.1517/14656566.2014.913570. 